\title{
BMJ Open Demographic and socioeconomic disparity in nutrition: application of a novel Correlated Component Regression approach
}

\author{
Ala'a Alkerwi, ${ }^{1}$ Céderic Vernier, ${ }^{1}$ Nicolas Sauvageot, ${ }^{1}$ Georgina E Crichton, ${ }^{1,2}$ \\ Merrill F Elias ${ }^{3,4}$
}

To cite: Alkerwi A, Vernier $\mathrm{C}$, Sauvageot N, et al. Demographic and socioeconomic disparity in nutrition: application of a novel Correlated Component Regression approach. BMJ Open 2015;5:e006814. doi:10.1136/bmjopen-2014006814

- Prepublication history and additional material is available. To view please visit the journal (http://dx.doi.org/ 10.1136/bmjopen-2014006814).

Received 6 October 2014 Revised 10 April 2015 Accepted 13 April 2015

CrossMark

For numbered affiliations see end of article.

Correspondence to Dr Ala'a Alkerwi; alaa.alkerwi@crp-sante.lu

\section{ABSTRACT}

Objectives: This study aimed to examine the most important demographic and socioeconomic factors associated with diet quality, evaluated in terms of compliance with national dietary recommendations, selection of healthy and unhealthy food choices, energy density and food variety. We hypothesised that different demographic and socioeconomic factors may show disparate associations with diet quality.

Study design: A nationwide, cross-sectional, population-based study.

Participants: A total of 1352 apparently healthy and non-institutionalised subjects, aged 18-69 years, participated in the Observation of Cardiovascular Risk Factors in Luxembourg (ORISCAV-LUX) study in 20072008. The participants attended the nearest study centre after a telephone appointment, and were interviewed by trained research staff.

Outcome measures: Diet quality as measured by 5 dietary indicators, namely, recommendation compliance index (RCI), recommended foods score (RFS), nonrecommended foods score (non-RFS), energy density score (EDS), and dietary diversity score (DDS). The novel Correlated Component Regression (CCR) technique was used to determine the importance and magnitude of the association of each socioeconomic factor with diet quality, in a global analytic approach.

Results: Increasing age, being male and living below the poverty threshold were predominant factors associated with eating a high energy density diet. Education level was an important factor associated with healthy and adequate food choices, whereas economic resources were predominant factors associated with food diversity and energy density.

Conclusions: Multiple demographic and socioeconomic circumstances were associated with different diet quality indicators. Efforts to improve diet quality for high-risk groups need an important public health focus.

\section{BACKGROUND}

Socioeconomic disparity in nutrition is well documented $^{1-5}$ which helps to explain some of the observed social inequalities in health. $^{2}{ }^{6}$ People with high socioeconomic status (SES) are more likely to have healthier food habits, whereas people with low SES have dietary profiles less consistent with nutritional recommendations or dietary guidelines, hence contributing to their poorer health status. ${ }^{6}{ }^{7}$ Therefore, both social inequity and diet quality, reflected by healthy dietary behaviours are areas of active public health concern.

Despite the importance of these two areas, research with regard to SES is still challenging and characterised by a number of conceptual and methodological problems that hinder advances in knowledge about how and why SES is related to diet. ${ }^{89}$ A single 'best' indicator approach, to determine social classification among societies is not theoretically compelling because it may emphasise a particular aspect of social stratification which may be only relevant to specific health outcomes $^{10} 11$ and at different stages of the life course. ${ }^{12}$ The most widely used SES indicators (education, occupation and income $)^{8913}$ are limited in their ability to capture the complex multidimensional forces that dominate social structure. ${ }^{14}$ While education and occupation are markers of social relationships and command over life-long skills, income is more indicative of a current standard of living. ${ }^{15}$ Additionally, these traditional SES are interrelated, which makes it difficult to determine the specific contribution of each factor to food choices. $^{2} 16$

Beyond household income, Daly et $a l^{15}$ suggest wealth as a standard economic component for monitoring links between SES and health. Household income consists of a flow of resources over a defined time period, whereas wealth captures the accumulated stock of assets (housing, cars, investments, inheritance and pension rights or economic 
reserves over the life course), although both are positively correlated. ${ }^{15}$

Another challenge to SES research is that these indicators are not interchangeable online; ${ }^{17}$ both cumulative effects $^{12} 18$ and unique contributions from each indicator may exist. ${ }^{9} 15$ Thus, it is still difficult to directly attribute the observed variation in diet quality to a specific SES indicator because different indicators may show disparate effects on food habits. ${ }^{13}$

The objective of the present study was to examine the simultaneous association of a range of demographic and socioeconomic factors with diet quality, as measured by several selected dietary indicators. The importance and explanatory power (power of independent contribution) of each SES factor with regard to the quality of diet was explored by using the novel Correlated Component Regression (CCR) ${ }^{19}$ technique. The CCR provides an alternative method to capture important suppressor variables among a set of predictors, especially when these are moderately to highly correlated, by dealing with the problems of confounding and the effects of multicollinearity. ${ }^{19}$ The CCR helps to ascertain the classification of key SES indicators that influence diet quality according to their importance, thus providing better performance than traditional regression techniques.

The findings are important to gain a better understanding of socioeconomic disparities in nutrition with the consequent impacts on health in order to develop strategies aimed at tackling the problem of SES disparities in nutrition in a global context.

\section{METHODS}

Studied population

Analyses were conducted on data from the Observation of Cardiovascular Risk Factors in Luxembourg (ORISCAVLUX), a nationwide nutritional population-based study. A comprehensive description of the ORISCAV-LUX survey design sampling methods has been published elsewhere. ${ }^{1620} 21$ Briefly, a random sample stratified by age (18-69 years), sex and district of residence was selected from the national health insurance registry. A total of 1432 participants were recruited with a participation rate (32.2\%) corresponding to the theoretically expected rate on which the sample size was calculated..$^{21}$ The participants attended the nearest study centre after a telephone appointment, and were interviewed by a trained member of the research staff. After data cleaning, particularly for poorly completed food frequency questionnaire (FFQ), data from 1352 participants were available for analyses.

\section{Independent demographic and socioeconomic variables}

Self-reported information on demographic and socioeconomic variables were collected via a questionnaire, including age, sex, country of birth, education level, marital status, work status, monthly household income, and perceived wealth. Education level, based on the highest diploma obtained, was classified into three groups: 'tertiary level' equivalent to university or more; 'secondary level' equivalent to classical or technical qualification and 'primary level' corresponding to nonacademic qualification (no diploma, at least 9 years of mandatory schooling). Marital status was recorded into either: 'live alone' which included single, divorced or widowed subjects; and 'living with partner'. Work status was classified as 'employed' comprising participants currently engaged in a remunerated occupation, 'unemployed' including students, 'retired/sick leave and disabled', and 'home duties/housewives'. The participants were classified according to their country of birth into four major groups: 'Luxembourg, 'Portugal', 'Other European country' and 'non-European country'. The Portuguese are representing the major European immigrant community in Luxembourg, which constituted about $16.1 \%$ of the total population of Luxembourg in $2011 .{ }^{22}$ Economic status was ascertained by asking participants to select one of seven categories as best representing total household monthly income: $<€ 750$, €750-€1499, €1500-€2249, €2250-€2999, €3000$€ 4999, € 5000-€ 10000$ and $>€ 10000$ per month. The number of adults and children living in the same household was also ascertained. Adult Equivalent Income (AEI) was calculated as the ratio of the midpoint of the self-declared family income to the square root of the number of persons in the household. The risk of poverty was referred to the national AEI which is equivalent to $€ 1432$ per month, as published by the national institute of statistics (STATEC). The economic status variable was then dichotomised as: 'above poverty threshold' (APT) and 'below poverty threshold' (BPT). Wealth adequacy perception was assessed by asking the question "To what extent does your current income and other available resources allow you to provide for your needs?" and was classified as: 'difficult' or 'easy'.

\section{Dependent variables: diet quality measures}

Dietary intake was assessed using a validated semiquantified $\mathrm{FFQ}^{23} 24$ which collects information on the frequency and quantity (portion size) of 134 items consumed over the preceding 3 months of the interview. Research staff provided detailed instructions on how to complete the FFQ and then checked the correctness and completeness of the answers.

Five diet quality indicators were selected: the Recommendation Compliance Index (RCI), ${ }^{1}$ Recommended Food Score (RFS) ${ }^{25}$ non-Recommended Food Score (non-RFS), ${ }^{26}$ Energy Density Score (EDS) ${ }^{27}$ and Dietary Diversity Score (DDS) ${ }^{28}$ to cover the multidimensional nature of diet quality. ${ }^{29}$ Adherence to national dietary recommendations, appropriate food choices, energy density and food variety/diversity were identified as key elements of high-quality diets. ${ }^{27}$ 30-33

The previously developed $\mathrm{RCI}^{1}$ was used to evaluate a participant's compliance with national dietary recommendations. It is a composite of 13 food-based and nutrientbased components, and ranges between -0.5 (due to a 
negative half point for excessive salt intake) and 14 points (2 points for high daily fruit and vegetable servings), where a higher degree of adherence is indicated by higher scores.

The RFS and non-RFS, used in numerous past studies on diet quality ${ }^{25} 3435$ were used to assess food choices. They were computed following the methods of Kant et $a l^{25}$ and modified by Kaluza $e t a l^{35}$ The RFS gives an indication of the frequency of consumption of food items that are recommended to increase (good choices), based on the 2010 Dietary Guidelines for Americans. ${ }^{36}$ It comprised 18 food items (including fruit, vegetables, legumes, wholegrain cereal products, low fat dairy products, fish and nuts). One point was given for consumption of any of the recommended foods at least once per week, ${ }^{25}$ to give a total score out of 18. The non-RFS gives an indication of the frequency of consumption of foods that are recommended to reduce (bad choices). It comprised 14 food items, including processed meats, refined grains, solid fats, added sugars and alcohol. Consumption of nonrecommended foods at least 2-4 times per week was assigned a score of 1 ; otherwise 0 points were assigned, ${ }^{35}{ }^{37}$ to give a total non-RFS out of 14 , with a higher value indicating a higher consumption of nonrecommended food items.

Consistent with other studies, EDS was used as an indicator of diet quality. ${ }^{30} 31$ It was defined as the ratio of total energy intake over daily weight of total food consumed $(\mathrm{kcal} / \mathrm{g})$, based on all foods and beverages, excluding drinking water. ${ }^{27}$ By selecting the lower energy density option, one can eat a greater volume or weight of an isocaloric food. Therefore, a higher EDS indicates more energy per gram of food consumed.

Food variety (diversity), another dimension of diet quality, was measured as described by Kim $e t a l,{ }^{28}$ to form the DDS. It comprised two components: overall variety (daily consumption of at least one serving from each of the five food groups: meat/poultry/fish/egg, dairy products, grains, fruit and vegetables, 0-15 points) and variety within protein sources (meat/poultry, fish, dairy, beans and eggs, $0-5$ points), to give a total DDS of 20 points (optimal diversity). A diet that has variety within similar food groups, as well as overall variety, is believed to be superior to a diet with a monotonous source. ${ }^{28}$ Variety among protein sources is included to illustrate the benefits of including diverse sources of food in the diet from within the same food group. ${ }^{28}$ Each item within these food groups provides important nutrient and nonnutrient components (eg, essential fatty acids from the fish group and phytochemicals from the beans group).

\section{Ethical aspects}

The present study was conducted according to the guidelines laid down in the Declaration of Helsinki, and all procedures involving human subjects were approved by the National Research Ethics Committee and the National Commission for Private Data Protection. Written informed consent was obtained from all participants.

\section{Statistical analysis}

For descriptive purposes, diet quality indicators and participants' demographic and socioeconomic characteristics were compared by sex. Then, the diet quality indicators were compared by demographic and socioeconomic factors, and $\mathrm{p}$ values were calculated by using the $\chi^{2}$ test for categorical variables, the $\mathrm{t}$ test and Kruskal-Wallis test for normally and non-normally distributed variables, respectively.

The CCR analysis $^{38}$ was performed using XLStat V.2014.2.07, to identify the optimal demographic and socioeconomic factors associated with dietary outcomes. It allows simultaneous adjustment for the effect of each indicator on the other, and hence shows the independent and unique contribution of each indicator. Beside the traditional SES indicators of education, work status and income, country of birth, marital status and perceived wealth were included. All selected predictors were simultaneously introduced. The categorical variables were recoded as dummy variables. The referent variables for each indicator were as follows: 'women' for sex, 'live with partner' for marital status, 'employed' for work status, 'Luxembourg' for country of birth, 'above poverty threshold' for economic status and 'easy' for wealth adequacy perception. Education was coded in an ordinal ranking, from lowest to highest education ( $1=$ no diploma, $2=$ secondary level, $3=$ postgraduate education, in an increasing continuous order).$^{39}$ Mathematically, variable selection is based on a stepping-down procedure which initialises with the full model including all the variables and then gradually eliminates variables with the smallest standardised coefficients one at a time, resulting in a final model with a relatively small number of predictors. This method provides better prediction and coefficient estimates closer to the true values, than traditional stepwise regression approaches, which impose no regularisation. ${ }^{40}$ Compared with the Partial Least Square (PLS) method, the CCR provides easy interpretable parameter estimates. ${ }^{19}$ Variable importance was compared using both standardised regression coefficient $(\beta)$ and crossvalidation predictor counts that reflect the number of occasions where the variable appears as a predictor in regression models. The cross-validated $\mathrm{R}^{2}$ (CV-R2) measures the goodness of fit to describe how well the statistical models fit the selected set of predictors.

The descriptive and univariate analyses were performed by using PASW for Windows V.18.0 software (formerly SPSS Statistics). Results were considered significant at the $5 \%$ critical level $(\mathrm{p}<0.05)$.

\section{RESULTS}

\section{Description of demographic, socioeconomic and} dietary indicators

Significant sex-specific differences for education level $(\mathrm{p}=0.02)$ and work status $(\mathrm{p}<0.001)$ were observed. Women consumed significantly more recommended foods (higher RFS), and fewer non-recommended foods 
(lower non-RFS) $(\mathrm{p}<0.001)$. EDS and DDS were significantly higher in men than in women $(p<0.001$ and 0.007 , respectively) (table 1 ).

\section{Correlation between selected SES factors}

While the selected SES indicators were significantly intercorrelated $(p<0.05)$, sex was only correlated with education level and work status (table 2).

\section{Univariate associations between SES factors and dietary outcomes}

The selected diet quality indicators were significantly associated with different demographic and socioeconomic factors. The mean RFS increased with education level, and the non-RFS decreased (table 3).

\section{Modeling of SES factors to predict diet quality}

Figures 1-5 (referent tables are presented in online supplementary appendix A 1-5) depict the demographic and socioeconomic factors associated with diet quality according to their importance, that is, to the power of independent contribution. In general, age, sex, country of birth and education appeared to be the most consistent factors associated with diet quality, whereas economic, work and marital status were least frequently associated with diet quality.

Adherence to national dietary recommendations, as measured by the RCI, was associated with being Portuguese, increased age and higher education level. However, men, unemployed, living alone, below the poverty threshold, and with difficult wealth perception were all significant factors associated with low compliance to national recommendations (figure 1). Similarly, men, living alone, below the poverty threshold, and having a difficult wealth perception were also associated with a lower RFS (lower intakes of recommended foods) (figure 2). Male sex, living alone, and below the poverty threshold were positively associated with the non-RFS (higher intakes of non-recommended food items) (figure 3). DDS was inversely associated with living alone

Table 1 Demographic, socioeconomic characteristics and dietary indicators by sex, ORISCAV-LUX study, 2007-2008

\begin{tabular}{|c|c|c|c|c|}
\hline & $\begin{array}{l}\text { Men } \\
n=657\end{array}$ & $\begin{array}{l}\text { Women } \\
n=695\end{array}$ & $\begin{array}{l}\text { Total } \\
n=1352\end{array}$ & p Value \\
\hline \multicolumn{5}{|c|}{ Demographic and socioeconomic characteristics } \\
\hline Age & $44.3 \pm 0.5$ & $44.3 \pm 0.5$ & $44.3 \pm 0.4$ & 0.97 \\
\hline Education level ( $n=1338)$ & & & & 0.02 \\
\hline Primary & 149 (22.9) & $202(29.4)$ & $351(26.2)$ & \\
\hline Secondary & $324(49.8)$ & $308(44.8)$ & $632(47.2)$ & \\
\hline Tertiary & $178(27.3)$ & $177(25.8)$ & $355(26.5)$ & \\
\hline Country of birth $(n=1352)$ & & & & 0.27 \\
\hline Luxembourg & $401(61.0)$ & $421(60.6)$ & $822(60.8)$ & \\
\hline Portugal & $88(13.4)$ & $74(10.6)$ & $162(12.0)$ & \\
\hline Other European & $131(19.9)$ & $162(23.3)$ & $293(21.7)$ & \\
\hline Non-European & $37(5.6)$ & $38(5.5)$ & $75(5.5)$ & \\
\hline Work status (n1351) & & & & $<0.001$ \\
\hline Employed & $472(71.8)$ & 397 (57.2) & $869(64.3)$ & \\
\hline Not employed & $58(8.8)$ & $60(8.6)$ & $118(8.7)$ & \\
\hline Housewives & $2(0.3)$ & $172(24.8)$ & $174(12.9)$ & \\
\hline Retired or disabled & $125(19.0)$ & $65(9.4)$ & $190(14.1)$ & \\
\hline Marital status $(n=1352)$ & & & & 0.34 \\
\hline Live with partner & $474(72.1)$ & $484(69.6)$ & $958(70.9)$ & \\
\hline Live alone & $183(27.9)$ & $211(30.4)$ & $394(29.1)$ & \\
\hline Economic status $(n=1174)$ & & & & 0.97 \\
\hline Below poverty threshold & $127(21.4)$ & $125(21.5)$ & $252(21.5)$ & \\
\hline Above poverty threshold & 466 (78.6) & $456(78.5)$ & $922(78.5)$ & \\
\hline Wealth adequacy perception $(n=1279)$ & & & & 0.21 \\
\hline Easy & 483 (77.9) & $532(80.7)$ & $1015(79.4)$ & \\
\hline Difficult & $137(22.1)$ & 127 (19.3) & $264(20.6)$ & \\
\hline \multicolumn{5}{|l|}{ Diet quality indicators } \\
\hline $\mathrm{RCl}(\mathrm{n}=1234)$ & $6.7 \pm 0.09$ & $6.8 \pm 0.10$ & $6.8 \pm 0.07$ & 0.57 \\
\hline $\operatorname{RFS}(n=1338)$ & $9.7 \pm 0.12$ & $10.8 \pm 0.11$ & $10.2 \pm 0.08$ & $<0.001$ \\
\hline nRFS (n=1352) & $4.1 \pm 0.07$ & $3.2 \pm 0.06$ & $3.6 \pm 0.05$ & $<0.001$ \\
\hline ED $(n=1346)$ & $105.8 \pm 1.0$ & $98.1 \pm 1.1$ & $101.9 \pm 0.7$ & $<0.001$ \\
\hline $\mathrm{DDS}^{*}(\mathrm{n}=1352)$ & $16.1 \pm 0.10$ & $15.7 \pm 0.10$ & $15.9 \pm 0.07$ & 0.007 \\
\hline
\end{tabular}

Results are presented $\mathrm{N}(\%)$ for qualitative variables and mean \pm SE for quantitative variables. $p$ Value from $X$ test and $t$ test for qualitative and quantitative outcomes respectively. ${ }^{*} \mathrm{p}$ Value from Kruskal-Wallis non-parametric test.

DDS, Dietary Diversity Score; ED, Energy Density; n-RFS, non-Recommended Foods Score; ORISCAV-LUX, Observation of Cardiovascular Risk Factors in Luxembourg; RCI, Recommendation Compliance Index. 
Table 2 Correlation* between the SES factors, ORISCAV-LUX study, 2007-2008

\begin{tabular}{|c|c|c|c|c|c|c|c|}
\hline & $\begin{array}{l}\text { Education } \\
\text { level }\end{array}$ & Age† & $\begin{array}{l}\text { Economic } \\
\text { status }\end{array}$ & $\begin{array}{l}\text { Marital } \\
\text { status }\end{array}$ & $\begin{array}{l}\text { Wealth } \\
\text { perception }\end{array}$ & $\begin{array}{l}\text { Country } \\
\text { of birth }\end{array}$ & $\begin{array}{l}\text { Work } \\
\text { status }\end{array}$ \\
\hline Sex & 0.02 & 0.74 & 0.96 & 0.31 & 0.21 & 0.27 & $<0.0001$ \\
\hline Education level & & $<0.0001$ & $<0.0001$ & 0.49 & $<0.0001$ & $<0.0001$ & $<0.0001$ \\
\hline Aget & & & 0.0029 & $<0.0001$ & 0.0013 & $<0.0001$ & $<0.0001$ \\
\hline Economic status & & & & 0.0051 & $<0.0001$ & $<0.0001$ & $<0.0001$ \\
\hline Marital status & & & & & 0.27 & 0.04 & $<0.0001$ \\
\hline Wealth perception & & & & & & $<0.0001$ & 0.0003 \\
\hline Country of birth & & & & & & & $<0.0001$ \\
\hline \multicolumn{8}{|l|}{ Work status } \\
\hline $\begin{array}{l}{ }^{*} p \text { Values from } \chi^{2} \text { tes } \\
\text { †Age was categorise } \\
\text { ORISCAV-LUX, Obse }\end{array}$ & in three cate & (18-29; & $\begin{array}{l}\text { 50-69). } \\
\text { Luxembourg. }\end{array}$ & & & & \\
\hline
\end{tabular}

and with difficult wealth perception, but positively associated with being male and from Portugal (figure 4). EDS was inversely associated with increased age but positively associated with being male and living below the poverty threshold (figure 5).

\section{DISCUSSION}

This study explored the simultaneous role of several demographic and socioeconomic factors in relation to diet quality among a representative sample of the adult population in Luxembourg. It is one of a few adult population studies ${ }^{13}{ }^{41}$ which has directly examined the importance and magnitude of the effect of each SES factor using a global analytical approach.

In general, the most important demographic and socioeconomic circumstances independently associated with diet quality, as indicated by healthy choices and adherence to dietary guidelines, were age, sex, country of birth and education level. Economic resources and wealth perception also contributed, but to a lesser extent. Consistent with our previous findings, ${ }^{1}$ Portuguese participants seemed significantly more compliant with national dietary guidelines and were more likely to select healthy and diverse food items, than other Europeans and non-Europeans. However, our previous findings showed that Portuguese participants were more overweight and obese compared with Luxembourgers. ${ }^{42}$ These findings are consistent with a French study, ${ }^{43}$ suggesting that obese individuals had greater compliance with national dietary guidelines than those with normal weight. This may be due to their awareness of their weight status which has led them to change their eating habits accordingly, or it may be that overweight people under-report poor choices and over-report healthy choices.

As may be expected, living alone with difficult wealth perceptions were independent discriminating factors, associated with decreased dietary variety. Limited financial resources and an absence of family life may explain the restricted access to diverse food choices. Good perceived wealth may indicate access to better quality material resources such as healthy foods, whereas the absence of good perceived wealth may negatively affect the appropriateness and diversity of choices. Wealth is higher for families with histories of higher earnings, more savings and, in some cases, fewer expenditures on healthcare. ${ }^{15}$ However, wealth perception by the individual may also be influenced by one's needs, love of money, level of aspirations and materialistic inclinations. ${ }^{44}$ Recent research has shown that two dimensions of money attitudes affect the subjective perception of wealth: the individuals' perceived financial control (the ability to budget, monitor and control their money), and money anxiety (worry and indecisiveness regarding money-related issues). ${ }^{44}$ This cumulative and dynamic nature of socioeconomic structures, ascertained by wealth as perceived by the individual, is rarely considered in epidemiological studies.

Additionally, this study showed that being male, younger and living below the poverty threshold were predominant factors associated with eating a high energy density diet. An often cited reason for poor eating patterns among low-income households is the cost of healthy food. ${ }^{30}{ }^{45}$ In the USA, more affluent populations consume higher quality diets than do disadvantaged populations. ${ }^{46}$ People with financial constraints are likely to consume fewer fruits and vegetables and consume more high energy dense foods of lower quality (eg, processed) that are high in added sugars and saturated fat. $^{47}$

Globally, our results support previous findings reporting socioeconomic gradients in dietary intake. ${ }^{48}$ The US research has also shown associations between living below the poverty threshold with more unhealthy/less healthy food choices and being less likely to meet dietary recommendations. ${ }^{49}$ Low education and limited economic resources may jointly contribute to people choosing low-cost, unhealthy, energy-dense foods, high in fat and sugar. Generally speaking, poor socioeconomic circumstances lead to poor health, which may be explained, in part, by less than optimal diet.

Several strong points characterise the present study. The data were derived from a recent nationwide sample of the general adult population. The CCR approach showed simultaneous factor-specific contributions to diet 


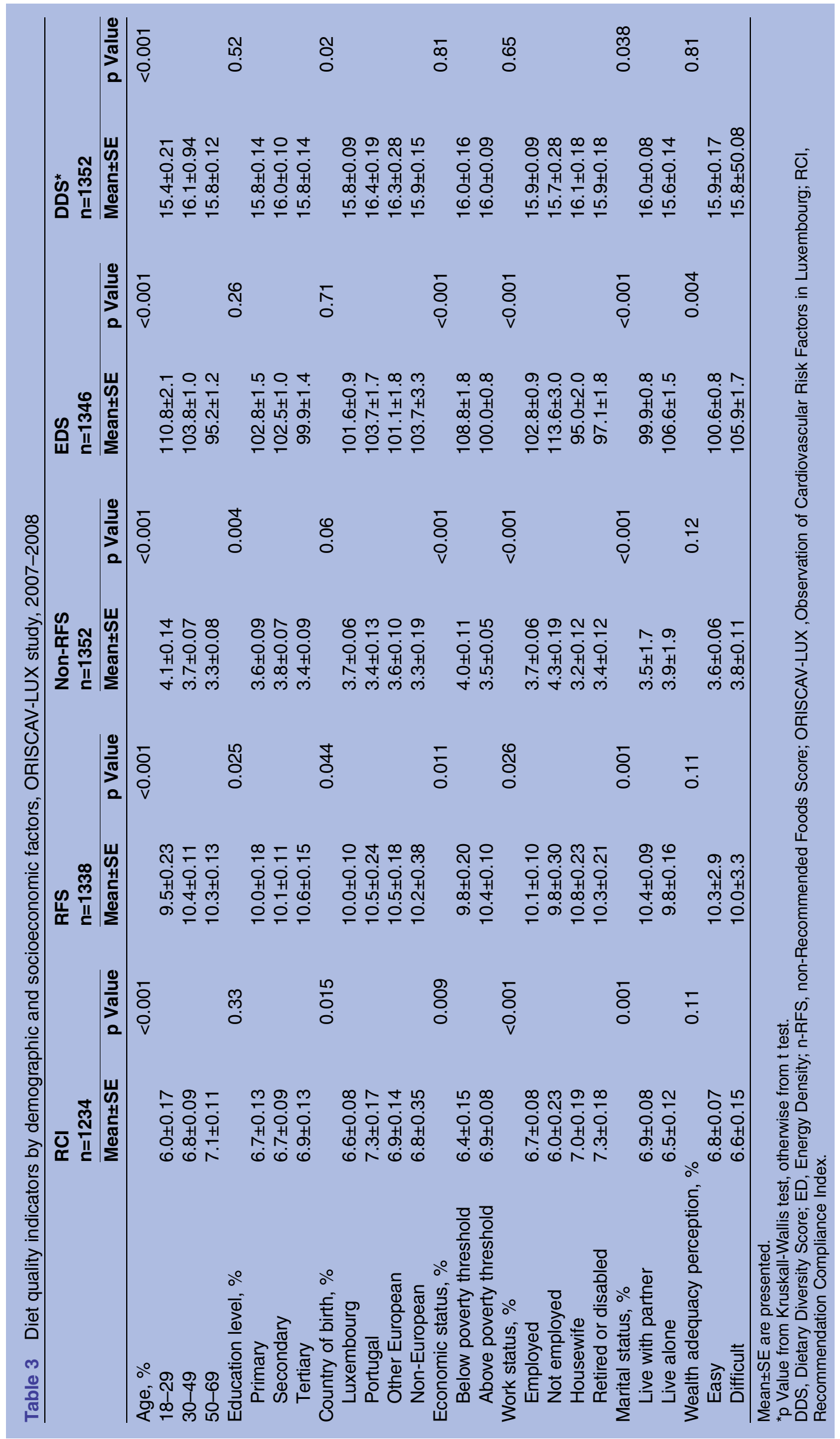


$\mathrm{RCl}$

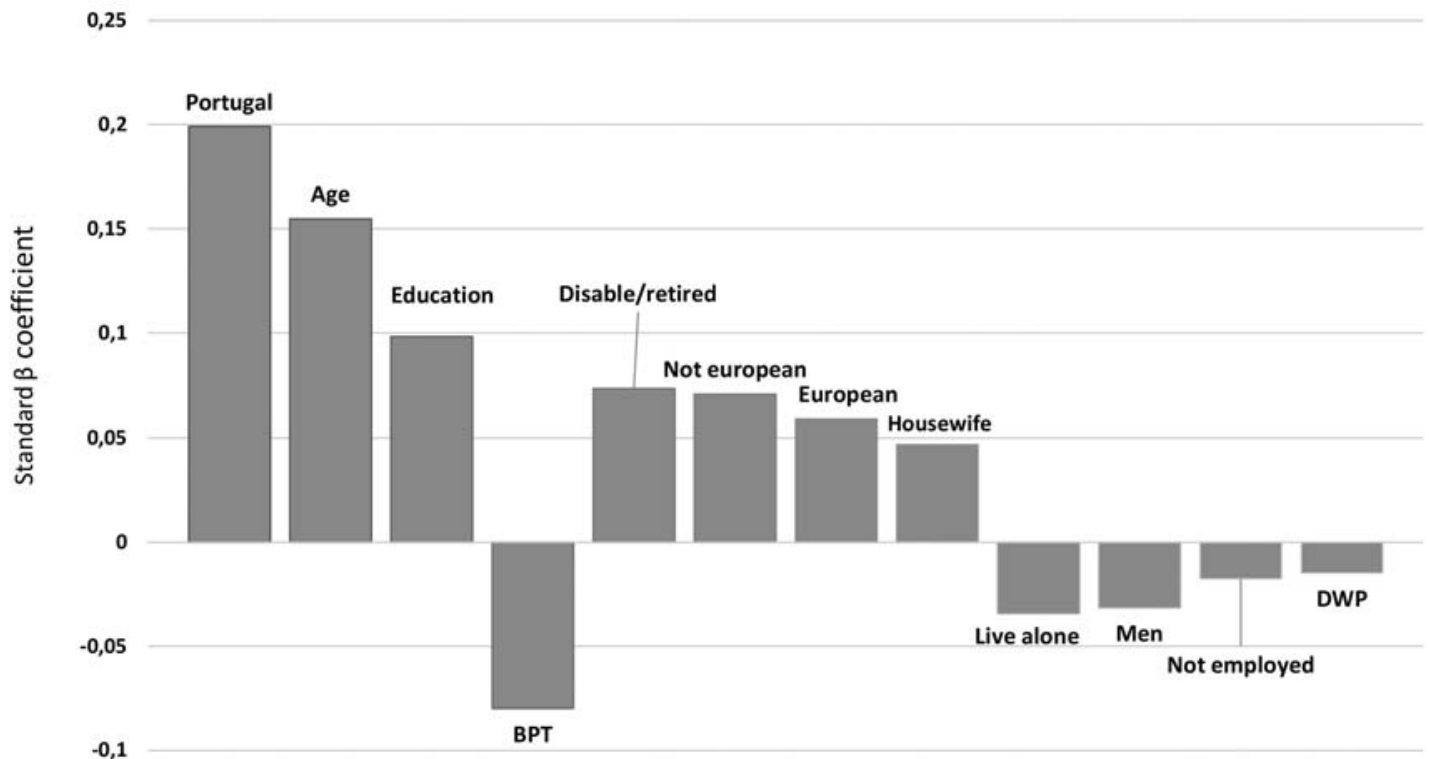

Figure 1 Demographic and socioeconomic factors associated with compliance with dietary recommendations (BPT, below poverty threshold; DWP, difficult wealth perception; RCI, Recommendation Compliance Index).

quality. It allowed us to measure the magnitude of the shared associations, not been measured in previous studies. ${ }^{9} 12$ Although the variances explained by each model were small, indicating that other factors would also be involved, our findings showed that multiple demographic and socioeconomic circumstances were independently associated with different diet quality indicators, and highlighted the importance of considering the overall context of SES when explaining nutritional disparities. It is widely agreed that the pathway mechanisms linking education, occupation and income with diet are conceptually distinct. ${ }^{9}$ For example, education may influence food choices by facilitating or constraining a person's ability to understand the information communicated by a healthcare professional or on food labels. ${ }^{9}$ Work status may affect diet through work-based cultures and social networks. ${ }^{12}$ Employment largely determines income and therefore, affordability of certain food

RFS

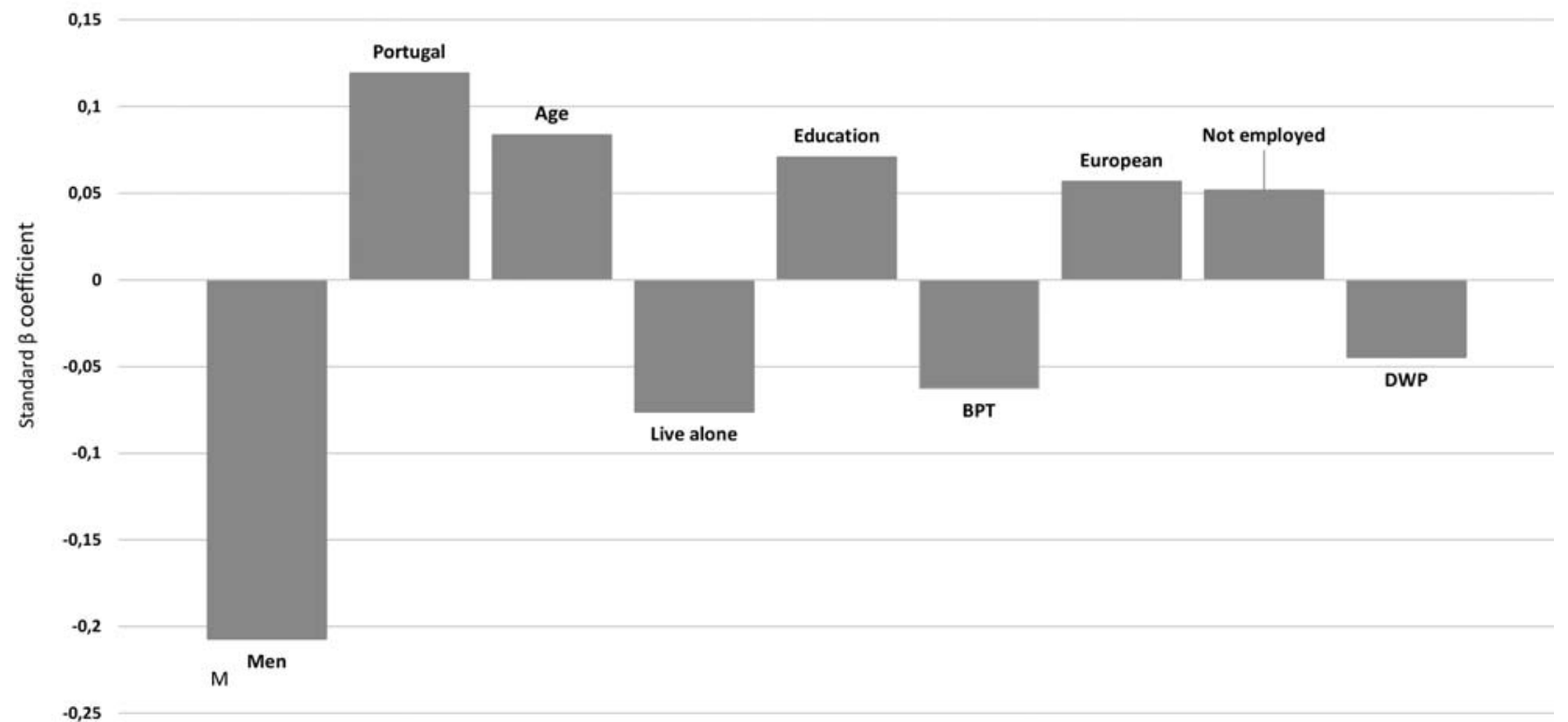

Figure 2 Demographic and socioeconomic factors associated with selecting healthy food choices (BPT, below poverty threshold; DWP, difficult wealth perception; RFS, Recommended Foods Score). 


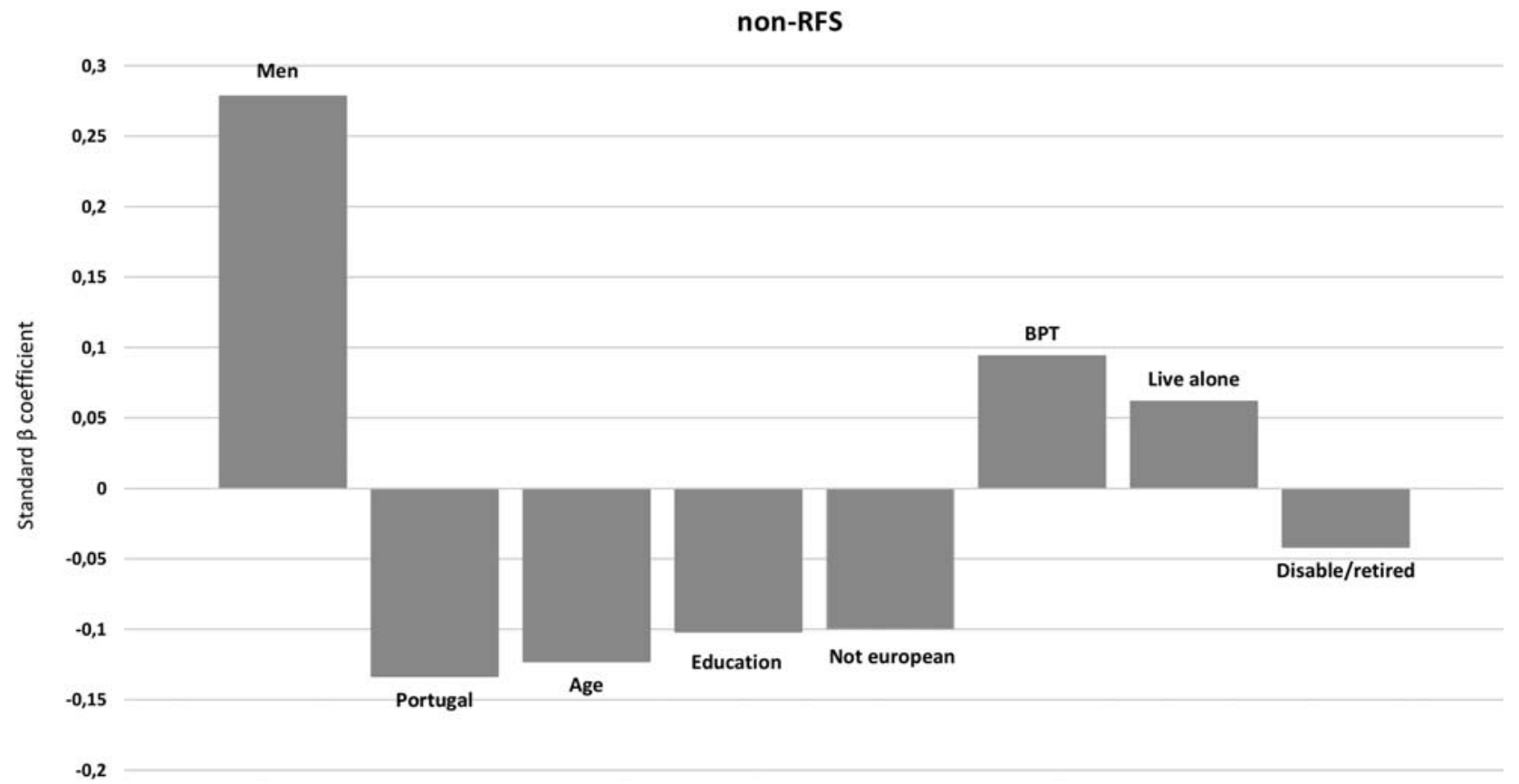

Figure 3 Demographic and socioeconomic factors associated with selecting unhealthy food choices (BPT, below poverty threshold; Non-RFS, non-Recommended Foods Score).

products, such as more healthy and nutritious food, ${ }^{15}$ suggesting that unequal distribution of resources may lead to nutritional disparities and consequent health inequity. This CCR procedure allowed the ability to distinguish shared and predictor-specific effect on diet quality. Identifying the key SES predictors is important to capture the variation in diet quality and to offer a better understanding of the underlying mechanisms relating to specific exposures. ${ }^{8}$ Compared with a single proxy indicator approach, our findings support the fact that SES is a multidimensional concept that should encompass other facets, mainly country of birth, marital status and wealth, as each reflects a different conceptual underpinning on how SES influences diet. $^{9}$ Likewise, age and sex were shown to be relevant SES indicators associated with various dietary quality scores.

Obtaining detailed overall diet quality assessments is challenging in population-based studies. ${ }^{50}$ Numerous

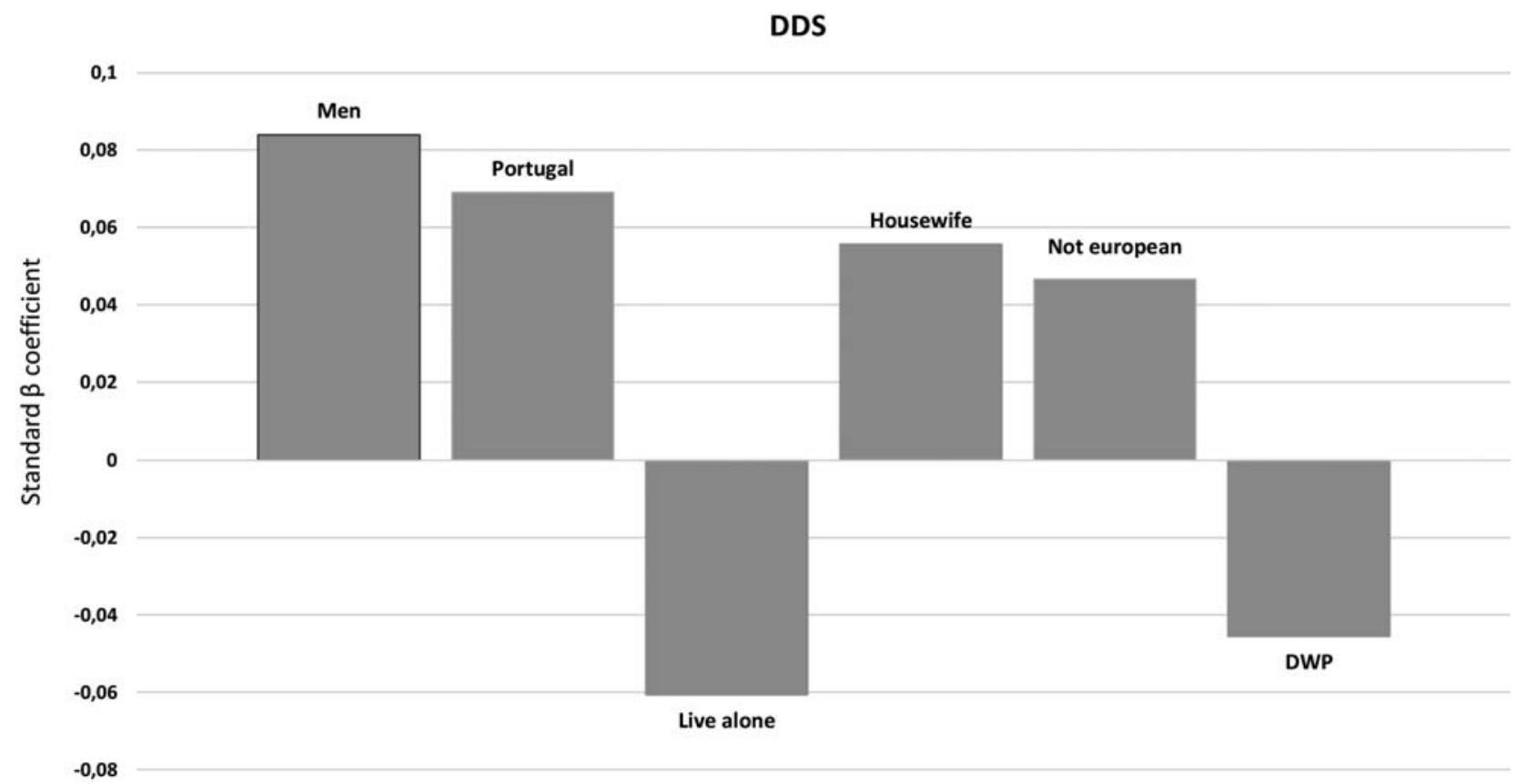

Figure 4 Demographic and socioeconomic factors associated with diverse foods items (DDS, Dietary Diversity Score; DWP, difficult wealth perception). 
EDS

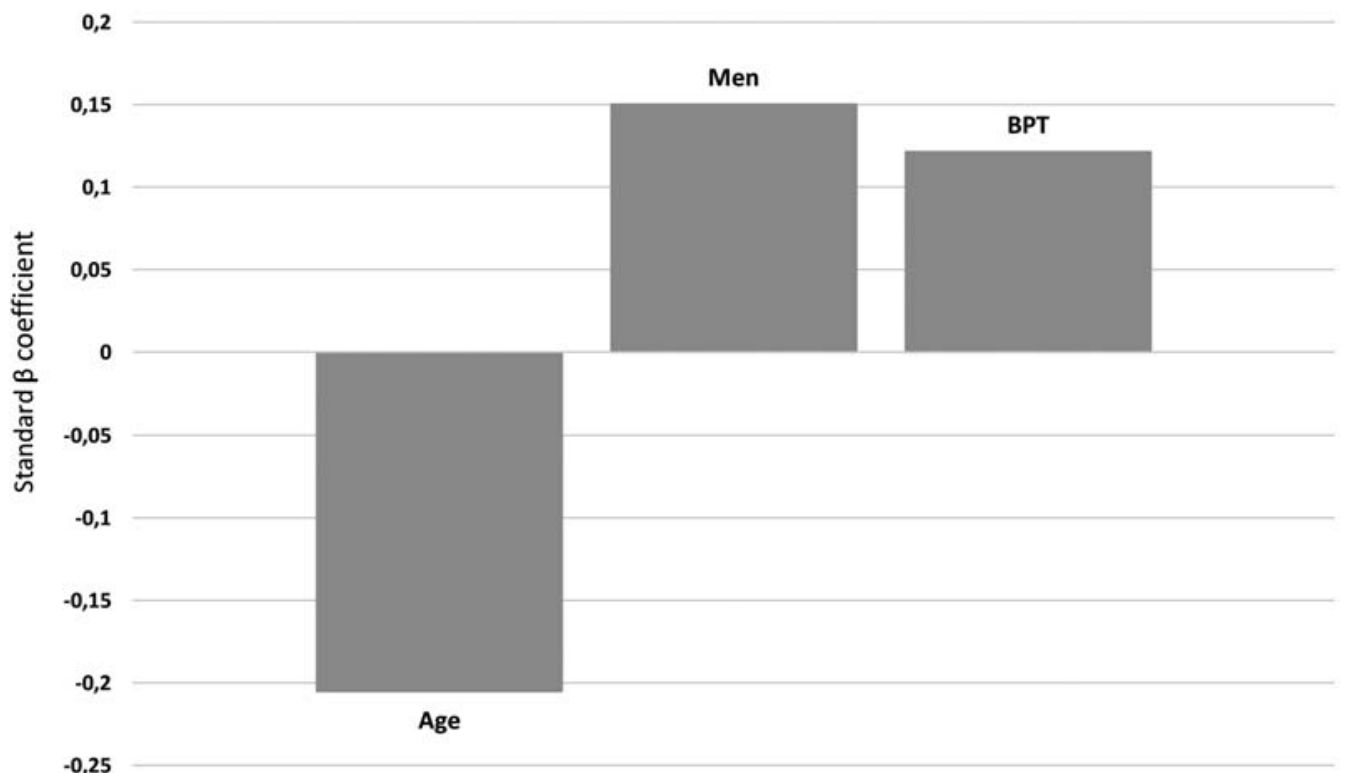

Figure 5 Demographic and socioeconomic factors associated with energy density (BPT, below poverty threshold; ED, Energy Density).

diet quality indices have been suggested in the literature to reflect various aspects of diet quality. ${ }^{51}$ These indices aim mainly to identify whether different population subgroups are consuming 'good/healthy' or 'detrimental/ unhealthy' foods, ${ }^{51}$ using a variety of definitions to describe these terms. From among a plethora of such descriptors, we focused on five indices to cover different aspects of diet quality, including compliance to national dietary recommendations, appropriate food choices, energy density and food variety/diversity. These five diet quality indices were highly correlated in the study population, ${ }^{52}$ probably because most of these indices focus on healthy dietary patterns; nevertheless, they may not be fully indicative of a healthy diet regardless of SES. Further research on which dietary indicators better predict nutritional status is warranted.

In calculations of energy density, the treatment of beverages is important. As beverages have a high water content, they tend to have a lower energy density than most foods, and may disproportionately influence dietary energy density values. ${ }^{53}$ The best method for calculating energy density depends on the purpose of the analysis, the outcome of interest, and the study population. Associations with weight or health status may possibly be weakened or missed ${ }^{54}$ when using energy density based on food and all beverages excluding water, however, this was not the objective of the present study. Using foods and all beverages, excluding water, is convenient and requires no special manipulation of the dietary intake data set. ${ }^{53}$

The selected diet quality indicators were calculated using a validated FFQ, where several quality control measures were undertaken to provide complete and coherent data. ${ }^{20}$ Two extensive validation studies ${ }^{23}{ }^{24}$ showed that the FFQ performed well in assessing intakes of several foods and micronutrients, and the observed correlations were within the range noted by other investigators. Additionally, intensive efforts were made to minimise dietary reporting inaccuracies through extensive control procedures. ${ }^{20}$

This study fills a knowledge gap and enhances the research on socioeconomic disparities in nutrition by addressing a novel method, defined as CCR, to identify the most important demographic and socioeconomic circumstances independently associated with diet quality. To the best of our knowledge, only one Australian study has used this CCR method to describe the socioeconomic gradients in children's diets. ${ }^{39}$

Further, several sensitivity analyses, by using linear regression and PLS methods, confirmed results obtained with CCR (data not shown). Consistent with CCR analyses, linear regression showed that being older, from Portugal or non-European countries, having higher education, and living above the poverty threshold were associated with a higher RCI. A higher RFS was also noticed in women, older people, from Portugal, with higher education. Concerning dietary diversity, higher scores were associated with male sex, being Portuguese, and those living with a partner. A higher non-RFS was associated with men living alone, whereas people with a higher education, living above the poverty threshold and from Portugal, were more likely to have a lower non-RFS. Similarly, the EDS was negatively associated with age, while male sex and people living below the poverty threshold were more likely to eat energydense foods. A PLS regression was also performed with diet quality scores as dependent variables and all selected demographic and SES factors as explicative variables. The first linear combination had high positive loadings for age, 
higher education, living above the poverty threshold, being housewives, and disabled or retired. High negative loadings were noted for men, living alone and being employed. This first linear combination was positively associated with the RCI, RFS and negatively associated with the non-RFS and energy density.

Certain shortcomings should also be recognised, related mainly to the current absence of a gold standard for dietary assessment. An optimal dietary intake assessment strategy still challenges nutrition research. ${ }^{55}$ Although the FFQ has been shown to be sufficiently convenient and inexpensive to use in large-scale, populationbased studies, ${ }^{56}$ responses rely on self-report and, therefore, are subject to imprecision (under-reporting and over-reporting) and biases related to social desirability. ${ }^{57}$

Other potential limitations include factors related to the cross-sectional design, which precludes establishment of the temporal sequence between socioeconomic circumstances and diet quality. Of course, all but prospective studies would be encumbered by this limitation. The relatively low response rate $(32.2 \%)$ did not influence the present findings, as a detailed study of non-participants showed comparable demographic and clinical characteristics of participants and non-participants, hence providing population-representative estimates. ${ }^{21}$

In conclusion, this study is a step towards moving the field of SES nutrition research forwards. Multiple demographic and socioeconomic circumstances were independently associated with diverse diet quality indicators. Age, sex, country of birth and education level were important factors associated with healthy and adequate food choices, whereas economic resources were associated with food diversity and energy density. From a public health standpoint, these findings are important in delineating the groups at risk in terms of their demographic and socioeconomic circumstances.

\section{Author affiliations \\ ${ }^{1}$ Luxembourg Health Institute L.I.H. (formerly Centre de Recherche Public Santé), Centre d'Etudes en Santé, Grand-Duchy of Luxembourg, Strassen, Luxembourg \\ ${ }^{2}$ Nutritional Physiology Research Centre, University of South Australia, Adelaide, Australia \\ ${ }^{3}$ Department of Psychology, University of Maine, Orono, Maine, USA \\ ${ }^{4}$ Graduate School of Biomedical Sciences and Engineering, University of Maine, Orono, Maine, USA}

Contributors AA was involved in the conception and design of the ORISCAV-LUX survey, coordinated the field data collection. All the authors fulfil the ICMJE guidelines, as regards: (1) substantial contributions to conception and design, analysis and interpretation of data; (2) drafting the article or revising it critically for important intellectual content; and (3) final approval of the version to be published.

Funding AA is supported by a grant from the FNR (Fond National de Recherche) for the project DIQUA-LUX, 5870404), Luxembourg. GEC is supported by a Sidney Sax Research Fellowship (National Health and Medical Research Council, Australia, grant number APP1054567).

Competing interests None declared.

Patient consent Obtained.

Ethics approval National Research Ethics Committee.
Provenance and peer review Not commissioned; externally peer reviewed.

Data sharing statement No additional data are available.

Open Access This is an Open Access article distributed in accordance with the Creative Commons Attribution Non Commercial (CC BY-NC 4.0) license, which permits others to distribute, remix, adapt, build upon this work noncommercially, and license their derivative works on different terms, provided the original work is properly cited and the use is non-commercial. See: http:// creativecommons.org/licenses/by-nc/4.0/

\section{REFERENCES}

1. Alkerwi A, Sauvageot N, Nau A, et al. Population compliance with national dietary recommendations and its determinants: findings from the ORISCAV-LUX study. Br J Nutr 2012;108:2083-92.

2. Darmon N, Drewnowski A. Does social class predict diet quality? Am J Clin Nutr 2008;87:1107-17.

3. Dubois L, Girard M. Social position and nutrition: a gradient relationship in Canada and the USA. Eur J Clin Nutr 2001:55:366-73.

4. Friel S, Kelleher CC, Nolan G, et al. Social diversity of Irish adults nutritional intake. Eur J Clin Nutr 2003;57:865-75.

5. Groth MV, Fagt S, Brondsted L. Social determinants of dietary habits in Denmark. Eur J Clin Nutr 2001;55:959-66.

6. James WP, Nelson M, Ralph A, et al. Socioeconomic determinants of health. The contribution of nutrition to inequalities in health. BMJ 1997;314:1545-9.

7. Smith GD, Brunner E. Socio-economic differentials in health: the role of nutrition. Proc Nutr Soc 1997;56:75-90.

8. Galobardes B, Lynch J, Smith GD. Measuring socioeconomic position in health research. Br Med Bull 2007;81-82:21-37.

9. Turrell G, Hewitt B, Patterson C, et al. Measuring socio-economic position in dietary research: is choice of socio-economic indicator important? Public Health Nutr 2003;6:191-200.

10. Kim MH, Kim MK, Choi BY, et al. Educational disparities in the metabolic syndrome in a rapidly changing society-the case of South Korea. Int J Epidemiol 2005;34:1266-73.

11. Silventoinen $\mathrm{K}, \mathrm{Pankow} \mathrm{J}$, Jousilahti $\mathrm{P}$, et al. Educational inequalities in the metabolic syndrome and coronary heart disease among middle-aged men and women. Int J Epidemiol 2005;34:327-34.

12. Galobardes B, Morabia A, Bernstein MS. Diet and socioeconomic position: does the use of different indicators matter? Int $\mathrm{J}$ Epidemiol 2001;30:334-40.

13. Lallukka T, Laaksonen $\mathrm{M}$, Rahkonen $\mathrm{O}$, et al. Multiple socio-economic circumstances and healthy food habits. Eur J Clin Nutr 2007;61:701-10.

14. Perel P, Langenberg C, Ferrie J, et al. Household wealth and the metabolic syndrome in the Whitehall II study. Diabetes Care 2006;29:2694-700.

15. Daly MC, Duncan GJ, McDonough $P$, et al. Optimal indicators of socioeconomic status for health research. Am J Public Health 2002:92:1151-7.

16. Alkerwi A, Donneau AF, Sauvageot N, et al. Dietary, behavioural and socio-economic determinants of the metabolic syndrome among adults in Luxembourg: findings from the ORISCAV-LUX study. Public Health Nutr 2012;15:849-59.

17. Geyer S, Hemstrom O, Peter R, et al. Education, income, and occupational class cannot be used interchangeably in social epidemiology. Empirical evidence against a common practice. $J$ Epidemiol Community Health 2006:60:804-10.

18. Evans A, Booth H, Cashel K. Sociodemographic determinants of energy, fat and dietary fibre intake in Australian adults. Public Health Nutr 2000;3:67-75.

19. Getting Started with Correlated Component Regression (CCR) in CORExpress, Copyright ( 2011 by Statistical Innovations Inc. All rights reserved (version: 9/9/2011).

20. Alkerwi A, Sauvageot N, Donneau AF, et al. First nationwide survey on cardiovascular risk factors in Grand-Duchy of Luxembourg (ORISCAV-LUX). BMC Public Health 2010;10:468.

21. Alkerwi A, Sauvageot N, Couffignal S, et al. Comparison of participants and non-participants to the ORISCAV-LUX population-based study on cardiovascular risk factors in Luxembourg. BMC Med Res Methodol 2010;10:80.

22. STATEC. Les Portugais au Luxembourg. 2011. http:// wwwstatistiquespubliclu/fr/publications/series/rp2011/2013/1813-portugais/indexhtml $\mathrm{N}^{\circ} 18$

23. Sauvageot N, Alkerwi A, Adelin A, et al. Validation of the food frequency questionnaire used to assess the association between 
dietary habits and cardiovascular risk factors in the NESCAV study. J Nutr Food Sci 2013;3:208.

24. Sauvageot N, Alkerwi A, Albert A, et al. Use of food frequency questionnaire to assess relationships between dietary habits and cardiovascular risk factors in NESCAV study: validation with biomarkers. Nutr J 2013;12:143.

25. Kant AK, Schatzkin A, Graubard BI, et al. A prospective study of diet quality and mortality in women. JAMA 2000;283:2109-15.

26. Michels KB, Wolk A. A prospective study of variety of healthy foods and mortality in women. Int J Epidemiol 2002;31:847-54.

27. Ledikwe JH, Blanck HM, Khan LK, et al. Low-energy-density diets are associated with high diet quality in adults in the United States. J Am Diet Assoc 2006;106:1172-80.

28. Kim S, Haines PS, Siega-Riz AM, et al. The Diet Quality Index-International (DQI-I) provides an effective tool for cross-national comparison of diet quality as illustrated by China and the United States. J Nutr 2003;133:3476-84.

29. Patterson RE, Haines PS, Popkin BM. Diet quality index: capturing a multidimensional behavior. J Am Diet Assoc 1994;94:57-64.

30. Aggarwal A, Monsivais $\mathrm{P}$, Cook AJ, et al. Does diet cost mediate the relation between socioeconomic position and diet quality? Eur J Clin Nutr 2011;65:1059-66.

31. Maillot M, Darmon N, Vieux F, et al. Low energy density and high nutritional quality are each associated with higher diet costs in French adults. Am J Clin Nutr 2007;86:690-6.

32. Krebs-Smith SM, Smiciklas-Wright $\mathrm{H}$, Guthrie HA, et al. The effects of variety in food choices on dietary quality. J Am Diet Assoc 1987;87:897-903.

33. Murphy SP, Foote JA, Wilkens LR, et al. Simple measures of dietary variety are associated with improved dietary quality. J Am Diet Assoc 2006;106:425-9.

34. Ahmed HM, Blaha MJ, Nasir K, et al. Low-risk lifestyle, coronary calcium, cardiovascular events, and mortality: results from MESA. Am J Epidemiol 2013:178:12-21.

35. Kaluza J, Hakansson N, Brzozowska A, et al. Diet quality and mortality: a population-based prospective study of men. Eur J Clin Nutr 2009;63:451-7.

36. U.S. Department of Agriculture and U.S. Department of Health and Human Services. Dietary Guidelines for Americans, 2010. 7th edn. Washington DC: US Government Printing Office, 2010.

37. Wengreen $\mathrm{HJ}$, Neilson $\mathrm{C}$, Munger R, et al. Diet quality is associated with better cognitive test performance among aging men and women. J Nutr 2009;139:1944-9.

38. Magidson JF. Correlated component regression: a prediction/ classification methodology for possibly many features. In American Statistical Association Proceedings, American Statistical Association, 2010.

39. Zarnowiecki D, Ball K, Parletta N, et al. Describing socioeconomic gradients in children's diets-does the socioeconomic indicator used matter? Int J Behav Nutr Phys Activ 2014:11:44.

40. Magidson J. Correlated component regression: a prediction/ classification methodology for possibly many features. (Reprinted from the 2010 American Statistical Association Proceedings with
Edits) Statistical Innovations Inc., 375 Concord Ave., Ste. 007, Belmont, MA 02478.

41. Boylan S, Lallukka T, Lahelma E, et al. Socio-economic circumstances and food habits in Eastern, Central and Western European populations. Public Health Nutr 2011;14:678-87.

42. Alkerwi A, Sauvageot N, Pagny S, et al. Acculturation, immigration status and cardiovascular risk factors among Portuguese immigrants to Luxembourg: findings from ORISCAV-LUX study. BMC Public Health 2012;12:864.

43. Malon A, Deschamps V, Salanave B, et al. Compliance with French nutrition and health program recommendations is strongly associated with socioeconomic characteristics in the general adult population. J Am Diet Assoc 2010;110:848-56.

44. Gasiorowska A. The relationship between objective and subjective wealth is moderated by financial control and mediated by money anxiety. J Econ Psychol 2014;43:64-74.

45. Cassady D, Jetter KM, Culp J. Is price a barrier to eating more fruits and vegetables for low-income families? J Am Diet Assoc 2007;107:1909-15.

46. Drewnowski A, Darmon N. The economics of obesity: dietary energy density and energy cost. Am J Clin Nutr 2005;82:265S-73S.

47. Drewnowski A, Darmon N. Food choices and diet costs: an economic analysis. J Nutr 2005;135:900-4.

48. Irala-Estevez JD, Groth M, Johansson L, et al. A systematic review of socio-economic differences in food habits in Europe: consumption of fruit and vegetables. Eur J Clin Nutr 2000:54:706-14.

49. Baker EA, Schootman M, Barnidge E, et al. The role of race and poverty in access to foods that enable individuals to adhere to dietary guidelines. Prev Chronic Dis 2006;3:A76.

50. Alkerwi A. Diet quality concept. Nutrition 2014;30:613-18.

51. Fransen HP, Ocke MC. Indices of diet quality. Curr Opin Clin Nutr Metab Care 2008:11:559-65.

52. Alkerwi A, Vernier C, Crichton GE, et al. Cross-comparison of diet quality indices for predicting chronic disease risk: findings from the Observation of Cardiovascular Risk Factors in Luxembourg (ORISCAV-LUX) study. Br J Nutr 2014:1-11.

53. Ledikwe JH, Blanck HM, Khan LK, et al. Dietary energy density determined by eight calculation methods in a nationally representative United States population. J Nutr 2005;135:273-8.

54. Mendoza JA, Drewnowski A, Christakis DA. Dietary energy density is associated with obesity and the metabolic syndrome in U.S. adults. Diabetes care 2007;30:974-9.

55. Kristal AR, Peters U, Potter JD. Is it time to abandon the food frequency questionnaire? Cancer Epidemiol Biomarkers Prev 2005;14:2826-8.

56. Schatzkin A, Kipnis V, Carroll RJ, et al. A comparison of a food frequency questionnaire with a 24-hour recall for use in an epidemiological cohort study: results from the biomarker-based Observing Protein and Energy Nutrition (OPEN) study. Int $J$ Epidemiol 2003;32:1054-62.

57. Hebert JR, Clemow L, Pbert L, et al. Social desirability bias in dietary self-report may compromise the validity of dietary intake measures. Int J Epidemiol 1995;24:389-98. 